\title{
OFICINAS DE ROBÓTICA OFERTADAS PARA ALUNOS DE ENSINO FUNDAMENTAL DE ESCOLAS PÚBLICAS: APRENDIZAGEM ATIVA E TECNOLOGIAS VIÁVEIS
}

DOI: 10.37702/2175-957X.COBENGE.2021.3697

ANA PAULA LIMA DOS SANTOS - anapaula.lima@ifmg.edu.br Instituo Federal de Minas Gerais

Rua Honória Maria Pires 34

36212-000 - Barroso - MG

Marcos Vinícius Silvestre Carneiro - m.viniciussilvestrec@gmail.com

Instituto Federal de Ciência Educação e Tecnologia

Avenida Abílio Machado 222

35570-000 - Formiga - MG

Daniel Santos Lopes - d_santoslopes@outlook.com

Instituto Federal de Educação Ciência e Tecnologia de Minas Gerais Campus

Formiga MG

Coronel Francisco Cambraia 459

37278-000 - Santana do Jacaré - MG

Gustavo Lobato Campos - gustavo.lobato@ifmg.edu.br

IFMG Instituto Federal de Minas Gerais

Alameda das Latânias 1236

31270-800 - Belo Horizonte - MG

Patrick Santos de Oliveira - patrick.oliveira@ifmg.edu.br

Instituto Federal de Minas Gerais

Av. Inhô Fidelis 510

35570-740 - Formiga - MG

Resumo: É consonante que o ensino possui um papel essencial na preparação dos alunos para o desenvolvimento de competências que atendam ao cenário atual, de grandes e rápidas inovações tecnológicas. No entanto, fatores como vulnerabilidade social, falta de identificação com o curso, desconhecimento da área de estudo e atuação profissional por meio dos discentes são alguns dos 
problemas encontrados, tanto na relação com o número de evasões, quanto na falta de interesse e motivação. Entendendo que a educação possibilita ampliar as oportunidades de crianças e jovens, é necessário empregar metodologias ativas e tecnologias possíveis e viáveis, despertando os alunos na busca de novos conhecimentos. Nesse contexto, o uso de tecnologias como a plataforma Arduino em conjunto com a robótica educacional, possibilita desenvolver habilidades essenciais para os alunos e profissionais do século XXI, as quais fazem parte da chamada Educação 4.0. A inclusão da robótica no ensino leva o aluno a pensar na essência do problema, promovendo o estudo de conceitos multidisciplinares, explorando a curiosidade e desenvolvendo uma aprendizagem significativa. Portanto, este trabalho apresenta a implementação e os resultados obtidos com a prática de oficinas de robótica de baixo custo desenvolvidas a partir de um projeto de extensão do IFMG campus Formiga, destinadas a alunos da rede pública de ensino fundamental da cidade de Formiga-MG. O objetivo principal foi incentivar os alunos na busca pelo conhecimento, apresentando-os as inúmeras possibilidades que um ensino na área técnica pode proporcionar, além de trabalhar e desenvolver de forma conjunta habilidades práticas, cognitivas e socioemocionais.

Palavras-chave: Extensão. Tecnologias Viáveis. Oficinas de Robótica. Aprendizagem Ativa. 


\section{OFICINAS DE ROBÓTICA OFERTADAS PARA ALUNOS DE ENSINO FUNDAMENTAL DE ESCOLAS PÚBLICAS: APRENDIZAGEM ATIVA E TECNOLOGIAS VIÁVEIS}

\section{INTRODUÇÃO}

É consenso que o ensino possui um papel essencial na preparação dos alunos para o desenvolvimento de competências que atendam ao cenário atual, de grandes e rápidas inovações tecnológicas, causadas pela quarta revolução industrial (Indústria 4.0), (MEC, 2019). Entendendo que a educação possibilita ampliar as oportunidades de crianças e jovens, é necessário inovar e implementar tecnologia na sala de aula, utilizando metodologias ativas e tecnologias possíveis e viáveis, despertando os alunos na busca de novos conhecimentos, (FABRI JÚNIOR et al., 2014).

Analisando-se, no entanto, o desenvolvimento de alunos que ingressam nos cursos técnicos integrados do IFMG Campus Formiga, verifica-se que estes possuem certa dificuldade em se adequar ao ritmo das atividades e forma de condução das aulas, (IFMG FORMIGA, 2019). Fatores como vulnerabilidade social, falta de identificação com o curso, desconhecimento da área de estudo e atuação profissional por meio dos discentes são alguns dos problemas encontrados, tanto na relação com o número de evasões, quanto na falta de interesse e motivação. Entendendo que a educação possibilita ampliar as oportunidades de crianças e jovens, é necessário empregar metodologias ativas e tecnologias possíveis e viáveis, despertando os alunos na busca de novos conhecimentos.

O processo de evasão escolar é complexo e multicausal (IFMG FORMIGA, 2019; IFMG, 2017; DORE et al., 2014). Dessa forma, faz-se necessário a prevenção para a evasão, que é um dos caminhos para reduzir o abandono escolar, para isso deve-se compreender, orientar e acompanhar o estudante, incluindo o momento em que esse realiza sua primeira escolha no campo da formação profissional, (DORE et al., 2014). A prevenção é um processo, pressupõe-se que o desenvolvimento de projetos que enfoquem as práticas de ensino de modo a valorizar a diversidade humana e o seu desenvolvimento num contexto maior da sociedade auxiliam nessa estratégia, (CONAE, 2010).

Dessa forma, a inserção de novas tecnologias no processo de ensino-aprendizado é uma preocupação atual, implementar tecnologia na sala de aula para atrair a atenção do aluno, diminuir a abstração, a evasão, o não entendimento dos conceitos básicos e apresentar as aplicações no dia a dia é um objeto educacional atual. Assim, é possível desenvolver um aprendizado significativo, baseado nas habilidades do século XXI, tais como: pensamento matemático, fazer para aprender (cultura maker), aprender a programar, planejar e executar projetos, espírito cooperativo, inventividade e criatividade, (POSITIVO, 2019). Para tanto, faz-se necessário o uso de ferramentas que possibilitem uma maior interação entre os conhecimentos adquiridos nas disciplinas teóricas e suas aplicações no mundo real, tornando a aprendizagem ativa, na qual o aluno torna-se 0 protagonista.

Nesse contexto, a robótica aplicada na educação contribui para o desenvolvimento de um ambiente de ensino mais dinâmico, prazeroso e estimulante, atuando como facilitador das informações e das ferramentas necessárias à busca de soluções, (MEGDA, MOREIRA e FASSBINDER, 2012). A robótica leva o aluno a pensar na essência do problema, promovendo $o$ estudo de conceitos multidisciplinares, estimulando a criatividade e a inteligência do educando, além de tentar motivá-lo aos estudos. 0 
professor deixa de ser o único e exclusivo provedor de informações para tornar-se o parceiro no processo de aprendizagem (ALMEIDA, 2013).

Uma das ferramentas que pode ser empregada para desenvolver sistemas robóticos didáticos é a plataforma Arduino. Essa ferramenta tem sido bastante utilizada, em particular no desenvolvimento de projetos de engenharia em cursos de graduação e médio (FABRI JÚNIOR et al., 2014; SILVEIRA JUNIOR, COELHO e SANTOS, 2017; PEROBA et al., 2018), permitindo a construção de protótipos versáteis e a um custo relativamente baixo.

O Arduino é uma ferramenta popular para o desenvolvimento de produtos de loT (Internet das coisas), bem como uma das ferramentas mais bem sucedidas para a educação STEM/STEAM, termo em inglês para o uso multidisciplinar de Ciência, Tecnologia, Engenharia, Artes e Matemática, (ARDUINO, 2019). STEAM é considerada uma metodologia baseada em projetos e disciplinas integradas, que tem o objetivo de melhorar o desempenho acadêmico e ajudar os alunos na compreensão do mundo de forma mais abrangente, desenvolvendo habilidades, tais como: criatividade, pensamento crítico, comunicação, flexibilidade, habilidades sociais e culturais e capacidade de lidar com diferentes situações; as quais fazem parte da chamada Educação 4.0, (POSITIVO, 2019). Assim, a prática do STEAM permite ao estudante a mobilização de habilidades e saberes de forma integrada, com autonomia, explorando a curiosidade e desenvolvendo uma aprendizagem significativa (SILVA et al., 2017).

Indo ao encontro do exposto, este artigo discorre sobre a implementação e os resultados obtidos com a criação de oficinas de robótica de baixo custo desenvolvidas dentro de um projeto de extensão no IFMG campus Formiga, executadas com a utilização da plataforma Arduino, focando em dinamizar o ensino e torná-lo mais atrativo. Cujo objetivo foi introduzir em escolas da rede pública de ensino fundamental da cidade de Formiga-MG uma tecnológica atualizada. Para, dessa forma, realizar inclusão digital, incentivar os alunos no estudo de áreas multidisciplinares, apresentando-os as inúmeras possibilidades que um ensino na área técnica pode proporcionar, além de trabalhar e desenvolver de forma conjunta habilidades práticas, cognitivas e socioemocionais, aumentando a motivação e consciência do papel da educação na própria formação como cidadãos e futuros profissionais.

\section{OBJETIVOS}

Com o desenvolvimento deste trabalho pretendeu-se promover curso da plataforma microcontrolada Arduino no desenvolvimento de projetos de robótica com tecnologia acessível para alunos do $8^{\circ}$ e $9^{\circ}$ ano de escolas públicas do município de Formiga-MG. Buscou-se aliar conhecimento científico e tecnológico, por meio de ação multidisciplinar, para o desenvolvimento de aprendizagem ativa. Podem ser citados os seguintes objetivos específicos:

- Desenvolver habilidades de alunos carentes da rede pública de ensino, por meio de um modelo de curso em caráter de oficinas de robótica, estimulando-os na busca pelo conhecimento;

- Inclusão digital, por meio da utilização da plataforma microcontrolada Arduino, para a qual foi necessário realizar montagens com circuitos eletrônicos e realizar programação em computador; 
- Auxiliar no amadurecimento educacional e humano dos estudantes da rede pública de ensino fundamental, capacitando-os com o objetivo de torná-los responsáveis por seu sucesso educacional;

- Formação de alunos do IFMG para as atividades ligadas ao ensino (preparação de roteiros práticos, preparação de aulas de laboratório, acompanhamentos das oficinas de robótica, etc.);

- Promoção de maior integração entre o IFMG e as escolas do município de Formiga, ampliando o conhecimento sobre o Instituto pela comunidade local.

\section{METODOLOGIA}

Inicialmente, foi realizada a seleção de dois alunos do ensino Técnico em Eletrotécnica de Nível Médio e dois alunos da Graduação em Engenharia Elétrica do IFMG para atuar como professor monitor nas oficinas de robótica. Estes alunos foram selecionados por meio de análise de currículo, entrevista e avaliação oral sobre conteúdos relativos ao projeto.

Os alunos selecionados para atuar no projeto ficaram encarregados de levantar lista de materiais disponíveis no Laboratório de Eletrônica do IFMG Campus Formiga, preparar os roteiros práticos adequados conforme materiais disponíveis. Assim como verificar a necessidade de instalação de bibliotecas e softwares (livres) nos computadores do laboratório. Os alunos foram orientados durante todo o desenvolvimento do projeto pelos professores orientadores.

Os roteiros práticos foram elaborados abordando os conhecimentos necessários para a realização das oficinas, trabalhando, de forma progressiva e interligada, os conhecimentos para alcançar o objetivo final, que é a construção de um robô com a utilização da plataforma Arduino. A linguagem foi adaptada para a realidade dos alunos do ensino fundamental.

Posteriormente, o projeto foi divulgado em duas escolas públicas da rede municipal de Formiga-MG, a saber: Arlindo de Melo e Centro de Atenção Integral à Criança (CAIC). Para isso, foram afixados cartazes no ambiente escolar e também houve a visita dos professores monitores e dos professores orientadores para explicar aos alunos do $8^{\circ}$ e $9^{\circ}$ ano as características das oficinas de robótica e a contribuição que 0 aprendizado desenvolvido teria para sua formação.

A seleção dos alunos interessados foi realizada mediante os critérios de análise socioeconômica adotados no IFMG para constatação de carência, por meio do preenchimento de formulário que considere múltiplas variáveis, tais como: renda, local e condição de moradia, condição de manutenção da família, entre outros. Dezesseis alunos foram selecionados, os quais demonstraram interesse e atendiam aos requisitos, formando uma turma, dentro do limite para realização de práticas no Laboratório de Eletrônica do Campus.

Após a seleção dos alunos, foi realizada uma reunião com pais e alunos, na qual foram passadas informações necessárias para 0 andamento das oficinas, tais como: roupas adequadas para acesso aos ambientes laboratoriais do Campus (visando segurança nas práticas), datas das oficinas e responsabilidades dos alunos atendidos.

Os roteiros elaborados foram utilizados nas oficinas de robótica. Os alunos bolsistas e voluntários (professores monitores) foram orientados durante todo o desenvolvimento do projeto pelos professores orientadores. Os roteiros práticos foram elaborados abordando os conhecimentos necessários para a realização das práticas, trabalhando de forma progressiva e interligada os conhecimentos para alcançar o objetivo 
final, que era a construção de um robô com a utilização da plataforma Arduino. A linguagem adotada foi adaptada para a realidade dos alunos do $8^{\circ}$ e $9^{\circ}$ ano do ensino fundamental.

Os roteiros trabalhados buscaram possibilitar a montagem dos seguintes sistemas:

- Semáforo com o uso de LED's;

- Sensor de temperatura;

- Sensor de ré de carro com o uso de sensor ultrassônico e buzzer;

- Carrinho robótico guiado por controle remoto;

- Carrinho robótico que detecta obstáculo por ultrassom.

As oficinas de robótica foram realizadas no IFMG Campus Formiga no $2^{\circ}$ semestre de 2019, entre os meses de Agosto e Novembro, no período vespertino, conforme cronograma apresentado na Tabela 1. As aulas, de caráter prático, foram ministradas com duração de duas horas. Tanto os docentes responsáveis pela execução do projeto quanto os professores-monitores ministraram as oficinas. As aulas foram ministradas de forma expositiva, abertas à participação dos discentes. A partir de uma explanação inicial sobre conceitos introdutórios de eletricidade, segurança, circuitos eletrônicos, lógica, Arduino, sensores, programação na IDE (Ambiente de Desenvolvimento) do Arduino e a ferramenta Tinkercad, utilizada para a construção e simulação dos circuitos. Em seguida, roteiros práticos foram apresentados e explicados previamente à realização das montagens por meio dos discentes, as quais tiveram sempre a orientação dos docentes responsáveis pelo curso. Para a conclusão do curso foi exigida uma frequência mínima de $75 \%$.

Tabela 1 - Cronograma das oficinas de robótica.

\begin{tabular}{cc}
\hline Aulas & Datas \\
\hline Oficina 1 - Noções básicas de prática com eletrônica & $05 / 09 / 2019$ \\
\hline Oficina 2 - Arduino (montagens e programação) & 12 e 26/09/2019 \\
\hline Oficina 3 - Arduino (sensores e atuadores específicos) & 03 e 17/10/2019 \\
\hline Oficina 4 -Torneio de robótica & 07 e 21/11/2019 \\
\hline Visita à JECT do IFMG Campus Formiga & 22,23 ou 24/10/2019
\end{tabular}

Fonte: Acervo dos autores.

Os conteúdos das oficinas destacados na Tabela 1 são descritos a seguir:

- OFICINA 1 - Circuitos eletrônicos básicos sem o uso do Arduino: noções de segurança em práticas e ambiente laboratorial com eletricidade, uso do protoboard, LEDs, resistores, fonte CC, multímetro e etc.;

- OFICINA 2 - Arduino 1: montagens simples com o uso de sensores e atuadores digitais e noções de programação utilizando a IDE do Arduino. Simulação no Tinkercad e montagem na plataforma física;

- OFICINA 3 - Arduino 2: montagem e programação utilizando sensores e atuadores analógicos, com variáveis analógicas e bibliotecas padrões; Simulação no Tinkercad e montagem na plataforma física;

- OFICINA 4 - Torneio de robótica: montagem e programação de robôs com o uso dos componentes trabalhados nas oficinas anteriores e torneio de robótica entre os grupos de trabalho.

- Visita à JECT: Os alunos visitaram o IFMG Campus Formiga durante a realização da IX Jornada de Ciência e Tecnologia, para assim entrarem em 
contato com os trabalhos que são desenvolvidos no campus. Além disso, os técnicos Evandro da Silveira Loschi e Ricardo José da Fonseca ensinaram um pouco da linguagem de programação Phyton para os alunos, por meio da criação de um jogo nos computadores do Laboratório de Informática do campus.

Para realização da Oficina 4 foram utilizados Kits Chassi Smart 2WD. Esse Kit é apresentado na Figura 1, o qual possui componentes utilizados para montagem e aplicações robóticas, educacionais e projetos com Arduino. Por meio deste kit robótico é possível desenvolver habilidades com o uso de sensor ultrassônico, servo motor, receptor infravermelho, controle remoto e motores de corrente contínua.

Figura 1 - Kit Chassi Smart 2WD.
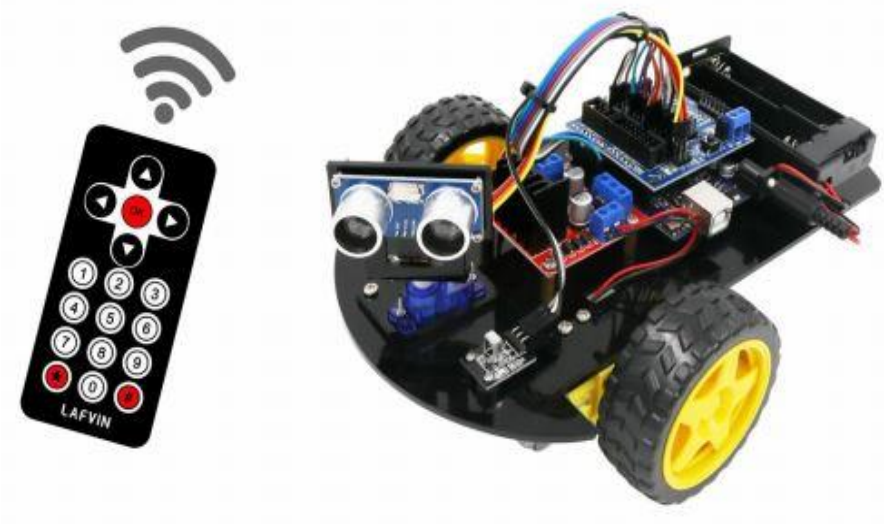

Fonte: Acervo dos Autores.

Como instrumentos de avaliação do processo de ensino-aprendizagem dos alunos participantes das oficinas, foi realizada avaliação formativa, sem caráter classificatório ou de atribuição de conceitos e notas. Pretendeu-se com a atividade não apenas avaliar o desenvolvimento discente no processo ensino-aprendizagem, mas também examinar a eficácia da estratégia didática empregada para alcançar os objetivos propostos, permitindo que fosse usada como instrumento de autoavaliação docente. Ao final do período de ministração das aulas, os alunos atendidos pelo projeto fizeram uma análise, por meio do preenchimento de questionário, do quanto as oficinas de robótica contribuíram para sua formação e preparo, o que pode ser melhorado, etc., o que permitiu uma avaliação da execução das oficinas, o vislumbre das reestruturações que deverão ser feitas para a continuidade da oferta da mesma.

\section{RESULTADOS E DISCUSSÃO}

Esta seção apresenta os resultados obtidos a partir da divulgação das Oficinas nas escolas à análise das respostas aos questionários fornecidas pelos alunos participantes.

\subsection{Divulgação das Oficinas de Robótica}

A divulgação das Oficinas para as escolas foi realizada contextualizando o assunto Robótica e Plataforma Arduino, assim como apresentando alguns dos componentes que seriam utilizados durante a realização das oficinas, conforme apresenta a Figura 2. 


\section{COBENGE

Figura 1- Divulgação do projeto para a escola Arlindo de Melo.
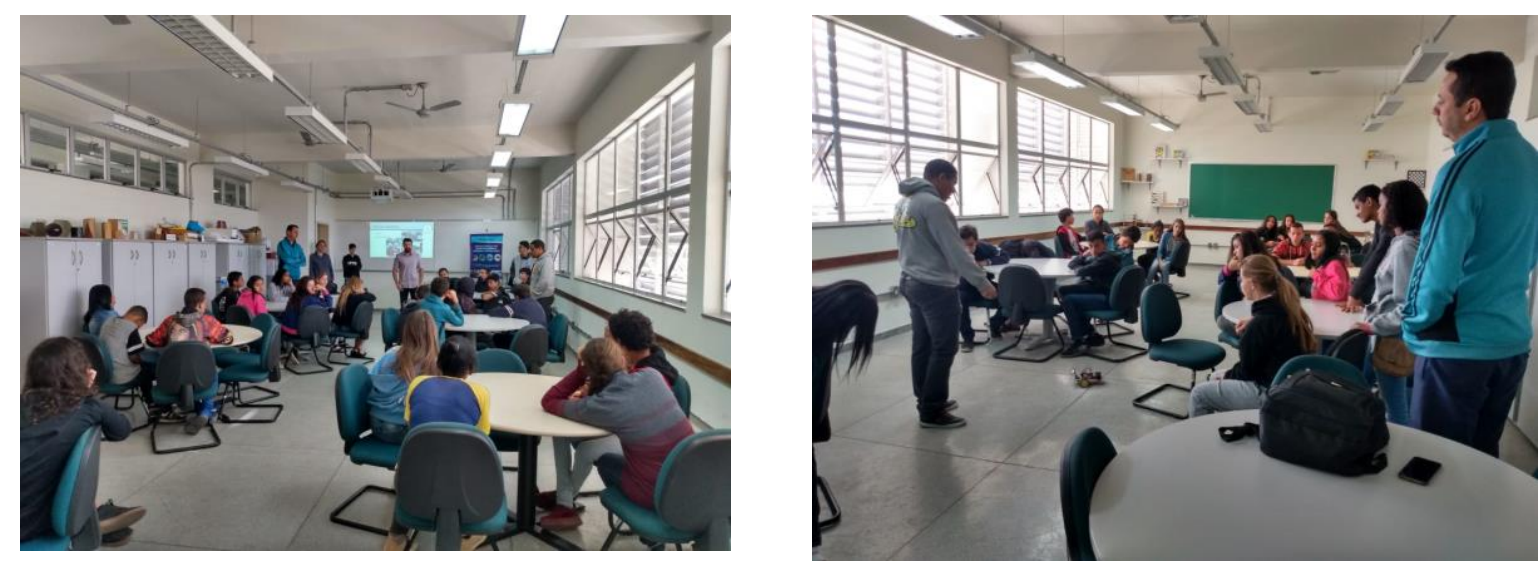

Fonte: Acervo dos Autores.

Após a divulgação das Oficinas, os questionários socioeconômicos foram entregues para que os alunos os preenchessem com um prazo de uma semana. Ao recolher estes questionários nas escolas verificou-se o interesse de 16 alunos em participar das oficinas, dentre os quais todos foram selecionados, sendo 6 alunos do 9e 0 restante do $8^{\circ}$ do ensino fundamental. Acredita-se que a dificuldade encontrada para preencher uma turma com 20 alunos (número total de vagas) deve-se principalmente à complexidade de locomoção dos alunos das escolas selecionadas, os quais, na maioria, moram na zona rural.

\subsection{Oficinas}

A realização das oficinas foi efetivada conforme conteúdo descrito e cronograma apresentado na Tabela 1. A Figura 3 apresenta algumas imagens destas oficinas. Durante as aulas era realizada uma chamada para computar a frequência dos alunos. Ao final do curso, houve 14 alunos concluintes, os quais possuíram frequência igual ou superior a $75 \%$.

Figura 3 - Realização das Oficinas no Laboratório de Eletrônica IFMG Campus Formiga.
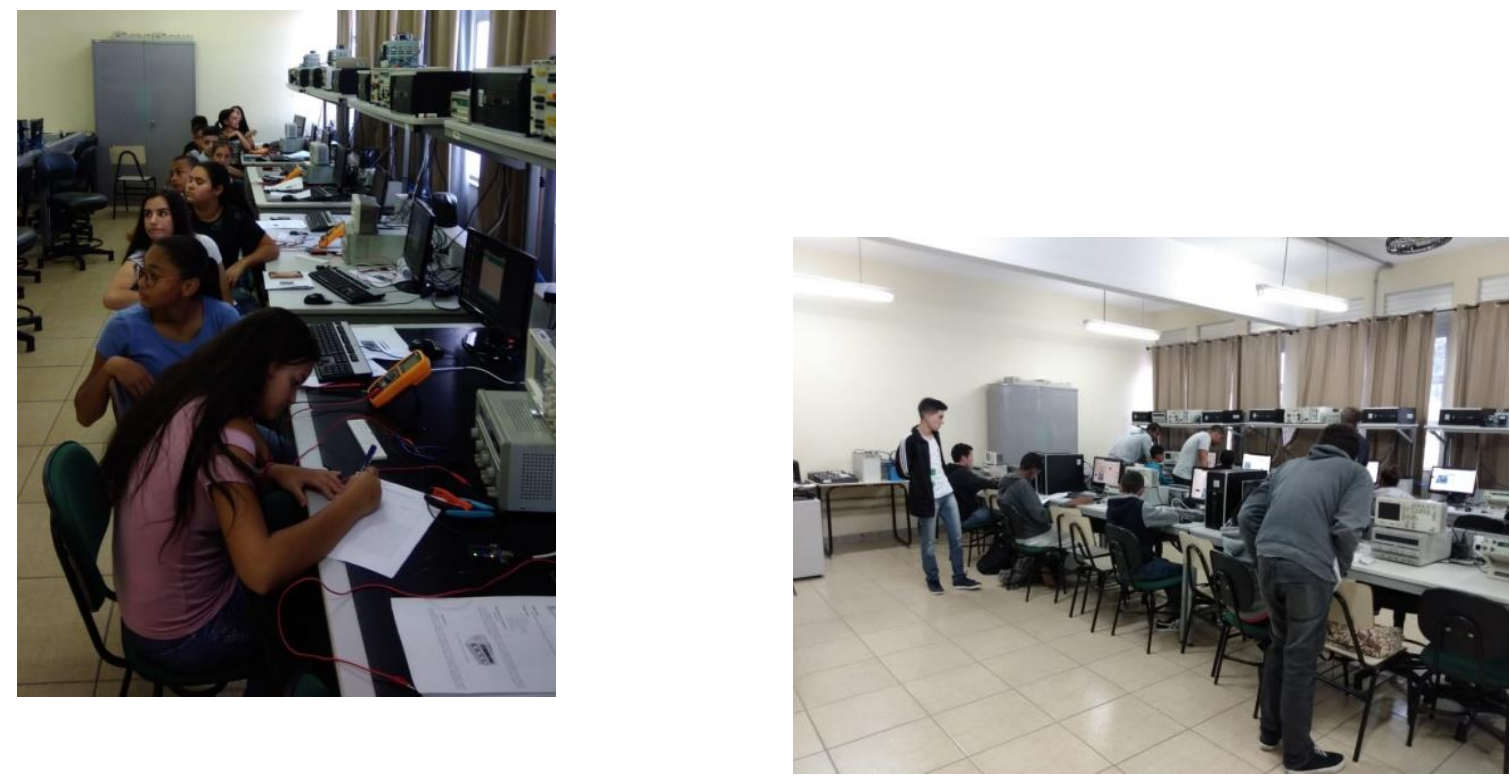


\section{COBENCE \\ 28 a 30 de SETEMBRO}
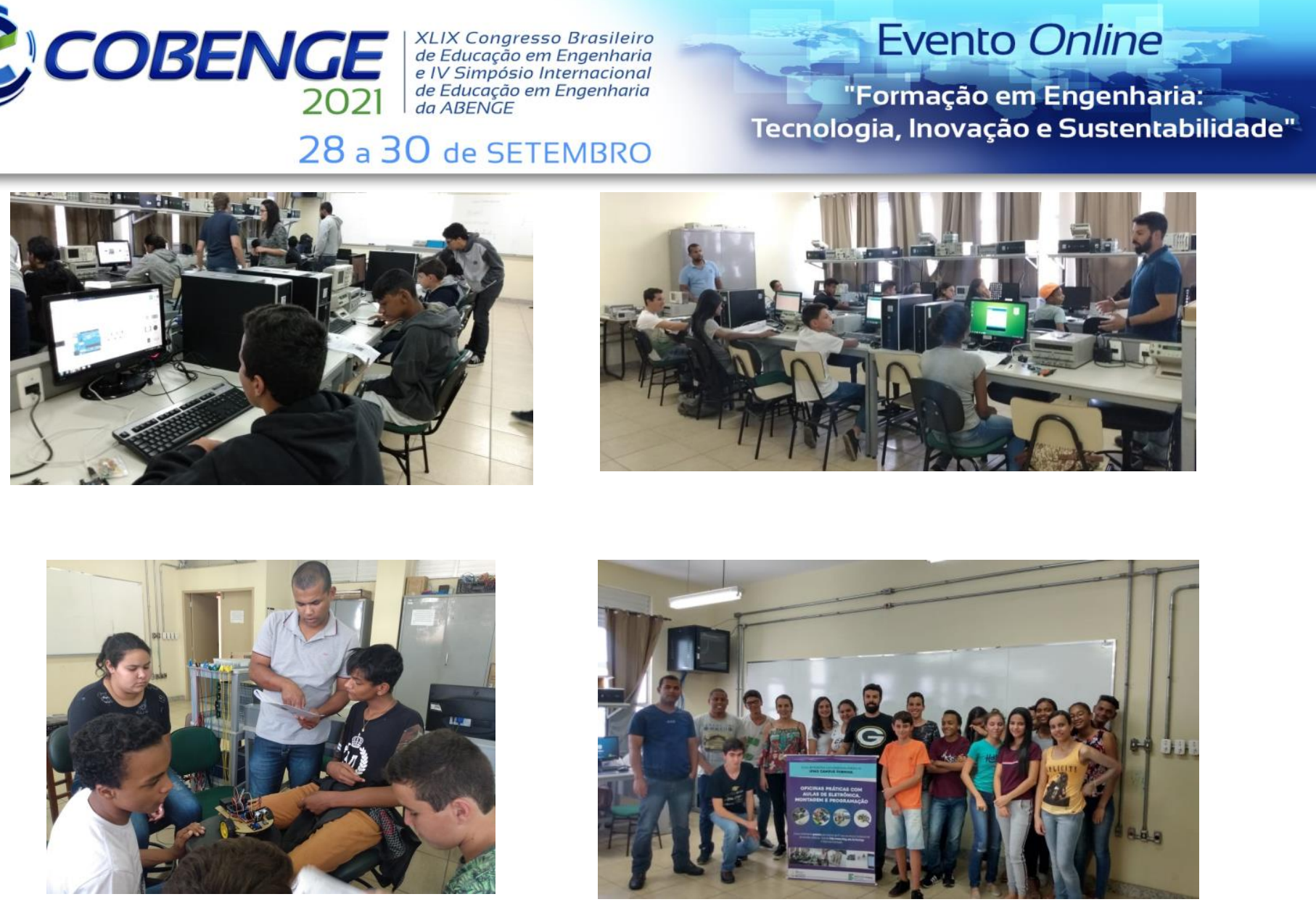

Fonte: Acervo dos Autores.

\subsection{Questionário Final}

Foi aplicado um questionário ao final do curso, o qual objetivava levantar o perfil dos alunos participantes e a opinião destes sobre o desenvolvimento do curso. As respostas ao questionário foram utilizadas para encontrar as fraquezas e pontos de melhorias para a implementação futura de novos cursos. A seguir são apresentadas algumas das respostas ao Questionário Final.

\section{Por que você se inscreveu para o cursinho de robótica IFMG:}

"Para aprender coisas novas."

"Porque acho a robótica interessante."

"Para me especificar na área."

"Pois estou com vontade de participar de algo novo."

\section{Você considerou a experiência no cursinho positiva ou negativa? Por quê?}

"Positiva, porque tudo que tem no mundo hoje envolve robótica."

"Positiva, aprendi coisas novas."

"Positiva, porque eu aprendi coisas que não sabia."

"Positiva, além de ajudar na coordenação motora incentiva a aprendizagem."

"Positiva, porque aprendi muitas coisas."

"Positiva, porque aprendi coisas novas e fiz novos amigos."

\section{O cursinho contribuiu para sua formação? De que maneira?}

"Sim. Ajudou a montar várias coisas que não sabia e me ensinou a trabalhar em equipe." 
"Não."

"Sim."

"Sim. Como tenho vontade de realizar uma faculdade na área de robótica."

"Sim. De maneira educacional."

Sugestões para o próximo cursinho de robótica: (apenas 1 aluno respondeu)

"Ser toda semana porque é muito bom."

Analisando tais respostas, juntamente com a avaliação formativa realizada durante as oficinas, é possível concluir que a ação do cursinho de robótica foi positiva. Seguem algumas justificativas para tal conclusão: os alunos participantes realizaram as atividades, se mostraram comprometidos e interessados, aprenderam conceitos novos e multidisciplinares; além disso, o feedback fornecido pelos alunos concluintes sobre "Você considerou a experiência do cursinho como positiva ou negativa?" foi $100 \%$ positivo. Ainda, $87,5 \%$ dos inscritos concluíram o curso. Adicionalmente, 2 alunos mostraram interesse em seguir os estudos no ensino técnico (33\% dos que possuíam o prérequisito), realizando a inscrição para o processo de seleção do IFMG.

Com relação ao tópico "O cursinho contribuiu para sua formação? De que maneira?", os autores pretendem, para os novos cursos, aplicar uma avaliação diagnóstica ao início e ao fim de cada curso e apresentar o feedback desta avaliação aos alunos, para que, dessa forma, estes possam identificar se houve ou não alguma evolução do seu conhecimento com a participação no curso.

\section{CONCLUSÃO}

Com o desenvolvimento deste projeto de extensão, com a criação e ministração das oficinas de robótica com tecnologias viáveis e metodologia ativa, foi possível perceber que a falta de interesse e, consequentemente, a evasão dos alunos podem ter como possíveis causas, tais como: o desconhecimento sobre a importância do tema estudado, metodologias que não apresentam aplicações reais e falta de interação com a realidade dos discentes. Tornar o aluno protagonista do seu aprendizado por meio de metodologias ativas e ferramentas atuais pode reverter este quadro e despertar 0 interesse para 0 estudo.

O aprendizado baseado no desenvolvimento de projetos práticos ajuda na assimilação de conteúdos novos, pois os alunos conseguem visualizar o funcionamento e não apenas fazer um modelo mental. Por meio da Plataforma Arduino foi possível realizar a montagem e simulação de projetos que buscaram construir desde um simples semáforo com LED's até a programação e montagem de um carrinho robótico que detecta barreiras, trabalhando conceitos multidisciplinares, tais como programação, lógica, circuitos elétricos e eletrônica; despertando a curiosidade, criatividade e trabalho em equipe.

Importante, ainda, destacar a experiência obtida pelos alunos bolsistas e voluntários na realização deste projeto, os professores monitores, os quais trabalharam conceitos técnicos, montagem de roteiros práticos e ministração de curso.

\section{Agradecimentos}

A todos os integrantes do Grupo de Pesquisa CNPq, GSE (Grupo de Soluções e Engenharia), pela interação e colaboração no desenvolvimento do presente trabalho. Aos 
técnicos do IFMG campus Formiga Evandro da Silveira Loschi e Ricardo José da Fonseca, pela disponibilidade em trabalhar com os alunos atendidos pelo projeto durante a JECT.

\section{REFERÊNCIAS}

ALMEIDA, Maria A. Possibilidades da robótica educacional para a educação matemática. Disponível em: http://www.diaadiaeducacao.pr.gov.br/portals/pde/arquivos/363-4.pdf. Acesso em: 4 de fevereiro de 2019.

ARDUINO, Plataforma Arduino. Disponível em: https://www.Arduino.cc. Acesso: 05 de fevereiro, 2019.

CONFERÊNCIA NACIONAL DE EDUCAÇÃO, 2010. Documento Final. Disponível em: http://conae.mec.gov.br/images/stories/pdf/pdf/documetos/documento final sl.pdf. Acesso em 21 de janeiro de 2019.

DORE, Rosemary et al. Evasão na educação: estudos, políticas e propostas de enfrentamento. Brasília: IFB/CEPROTEC/RIMEPES, 2014. Disponível em: http://www.fae.ufmg.br/rimepes/livros/Dore\%20et\%20al.\%20-\%202014\%20\%20Evasao\%20na\%20educacao\%20-\%20estudos,\%20politicas\%20e\%20propostas.pdf. Acesso em: 18 de janeiro de 2019.

FABRI JUNIOR, L. A. et al. Usando a plataforma Arduino para criação de kit pedagógico baseado em oficinas de robótica para introdução à engenharia no ensino médio. Perspectivas em Ciências Tecnológicas, v. 3, n. 3, maio 2014, p. 68-77.

IFMG. A Evasão Escolar no IFMG - Diagnóstico e diretrizes da política institucional para permanência e êxito dos estudantes. Relatório, 2017. Disponível em:

https://www.ifmg.edu.br/portal/links/relatorio-evasao-completo-rev6.pdf. Acesso em: 10 de janeiro de 2019.

IFMG FORMIGA. Indicadores e Estatísticas Educacionais do IFMG Campus Formiga. Disponível em: https://www.formiga.ifmg.edu.br/indicadores-educacionais. Acesso em: 15 de janeiro de 2019.

MEC (Ministério de Educação). 5 Fórum Lide de Educação e Inovação, 2018. Disponível em: http://portal.mec.gov.br/component/tags/tag/50121. Acesso em: 3 de fevereiro de 2019 .

MEGDA, Otávio A.; MOREIRA, Heber, R.; ARACELE, Garcia de O. F. Primeiros passos na implantação de projetos de robótica com Arduino em cursos técnicos da área de informática. Mostra Nacional de Robótica, 2018. Disponível em:

http://sistemaolimpo.org/midias/uploads/42b4fabc13660ec5b7a9e929fcab8702.pdf. Acesso em: 20 de janeiro de 2019.

PEROBA, Victor N. et al. Tecnologia Assistiva, o uso de Arduino na aprendizagem. XXII Encontro Latino Americano de Iniciação Científica, XVIII Encontro Latino Americano de 
Pós-Graduação e VIII Encontro de Iniciação à Docência - Universidade do Vale do Paraíba, 2018. Disponível em:

http://www.inicepg.univap.br/cd/INIC 2018/anais/arquivos/RE 11031256 01.pdf. Acesso em: 22 de janeiro de 2019.

SILVA et al. Educação Científica empregando o método STEAM e um makerspace a partir de uma aula-passeio. Lat. Am. J. Sci. Educ. v. 4, n. 2, 2017. Disponível em:

http://www.lajse.org/nov17/22034 Silva 2017.pdf. Acesso em: 20 de janeiro de 2019.

SILVEIRA JÚNIOR, Carlos R.; COELHO, Jeovane D. e SANTOS, Lays Sthefanne. Robótica nas aulas de matemática do ensino médio: uma proposta educacional e de baixo custo. Experiências em Ensino de Ciências v.12, n.5, 2017, p. 82-104.

POSITIVO. STEAM: uma metodologia que você precisa conhecer! Disponível em:

https://www.positivoteceduc.com.br/blog-inovacao-e-tendencias/steam-metodologia-

queprecisa-conhecer/. Acesso em: 15 de janeiro de 2019.

\title{
ROBOTICS WORKSHOPS OFFERED TO STUDENTS OF PUBLIC SCHOOLS: ACTIVE LEARNING AND VIABLE TECHNOLOGIES
}

\begin{abstract}
It is consonant that teaching has an essential role in preparing students for the development of skills that meet the current scenario, of great and rapid technological innovations. However, factors such as social vulnerability, lack of identification with the course, ignorance of the study area and field of work through students are some of the problems encountered, both in relation to the number of dropouts, and in the lack of interest and motivation. Understanding that education makes it possible to expand opportunities for children and young people, it is necessary to employ active methodologies and possible and viable technologies, awakening students in the search for new knowledge. In this context, the use of technologies such as the Arduino platform in conjunction with educational robotics, makes it possible to develop essential skills for students and professionals of the 21st century, which are part of the so-called Education 4.0. The inclusion of robotics in teaching leads the student to think about the essence of the problem, promoting the study of multidisciplinary concepts, exploring curiosity and developing meaningful learning. Therefore, this work presents the implementation and the results obtained with the practice of low-cost robotics workshops developed from an extension project of the IFMG campus Formiga, aimed at students from public elementary schools in the city of Formiga-MG. The main objective was to encourage students in the search for knowledge, introducing them to the countless possibilities that teaching in the technical area can provide, in addition to working and jointly developing practical, cognitive and socioemotional skills.
\end{abstract}

Keywords: Extension. Viable Technologies. Robotics workshops. Active Learning. 